\title{
Sugarcane Germplasm Collection in Western Cameroon
}

\author{
Doris Besem Arrey ${ }^{*}$, Afui Mathias Mih, Etake Sylvie Essomo \\ Department of Botany and Plant Physiology, Faculty of Science, University of Buea, City of Buea, Cameroon
}

Email address:

besemarrey@yahoo.ca (D. B. Arrey), afuimih@yahoo.com (A. M. Mih), essomo@yahoo.com (E. S. Essomo)

${ }^{*}$ Corresponding author

To cite this article:

Doris Besem Arrey, Afui Mathias Mih, Etake Sylvie Essomo. Sugarcane Germplasm Collection in Western Cameroon. American Journal of Life Sciences. Vol. 4, No. 6, 2016, pp. 139-145. doi: 10.11648/j.ajls.20160406.11

Received: October 4, 2016; Accepted: October 22, 2016; Published: November 17, 2016

\begin{abstract}
Sugarcane is losing its diversity owing to the many uses including biofuel production and genetic erosion. This study was carried out to collect sugarcane germplasm in Western Cameroon and to identify their uses and possible genetic erosion. Information was gathered from selected villages in two agro-ecological zones in Western Cameroon. The data were gathered through questionnaire, interviews and group discussion with pre-identified informants in the study area. Field trips were made to sugarcane fields to observe sugarcane landraces. A total of 290 questionnaires were distributed out to 203 males and 87 females of diverse age groups between 20 and 70 years. Majority of the population interviewed (37.9\%) were between the age 41 and 50 years. Eighty three percent of the population had attained primary education and were knowledgeable on sugarcane plant. Five sugarcane landraces were identified in the study. The landraces included 'Buea sugarcane', 'Strong canda', 'Strong bark', 'Yellow cane' and 'Bakweri sugarcane'. These canes had varied uses ranging from food to medicine. The highest fidelity value was recorded by 'Buea sugarcane'. There was genetic erosion of this plant due to lack of market, shortage of land, diseases and introduction of improved cash crops. The tendency of the uses of local sugarcanes in this study area point out that sugarcane plays a major role in the lives of the population. To minimize dangers of the emerging uses of sugarcane as biofuel and the threat to genetic erosion, the existing biodiversity needs to be conserved.
\end{abstract}

Keywords: Survey, Sugarcane Landraces, Uses, Agro-Ecological Zones, Western Cameroon

\section{Introduction}

Sugarcane (Saccharum officinarum Linn, the Noble cane) is an easy-to-grow plant that produces high yields of valuable products. In the Linneal binomial system of plant taxonomy, plants have been given the species name officinalis, officinale or officinarum. The adjectives Officinalis, officinale and officinarum, all mean 'used in medicine'. Sugarcane is adapted to an extremely wide range of climatic conditions and so it is cultivated throughout Tropical Africa [1]. Indigenous communities, otherwise known as tribal people, aboriginal people, or original inhabitants exist in many countries of the world and have their own traditional medicinal practitioners, who rely on a holistic approach for treatment of ailments involving plant, animal or insect parts together with amulets and incantations [2]. For the natives and traditional healers of the world, sugarcane is a valuable medicinal herb finding a significant place in alternative healing methods [3]. Sugarcane juice is widely used in India in the treatment of jaundice, hemorrhage, dysuria, anuria, and other urinary diseases. It is considered beneficial for the liver and is recommended that jaundice patients take in a large amount of sugarcane juice for immediate relief [4]. The genetic resources of this plant has been collected, conserved and documented in other parts of the world [5]. In Cameroon sugarcane is produced in home gardens and forest fields, where it is generally used as a snack. This plant also plays important cultural and economic roles [6]. Sugarcane is currently used as one of the feedstock for biofuels production. Most countries in Africa including Cameroon are still studying the opportunities of biofuels. Critics of the sugarcane ethanol industry have alleged that sugarcane ethanol drives up food prices and causes deforestation [7] leading to loss of biodiversity. The future of biofuels and the role they will play for agriculture and food security remain uncertain [8]. Increase in agriculture and industrial activities are causing enormous habitat disturbances. Most of the local varieties of sugarcane are under serious threat of genetic 
erosion. When choosing varieties, farmers consider yield potential as well as other production and consumption attributes.

A comparative assessment of sugarcane distribution and diversity in the earlier years in some major parts of the Southwest region clearly indicated the rapid erosion that is taking place. This area of diversity has been replaced by agriculture of other food crops and urban development. There is threat to genetic erosion due to cultivation of improved and selected clones to meet industrial needs. This threat is further accentuated by the emerging new uses of sugarcane as a source of biofuel, reason why there is need to document and save the existing biodiversity. The purpose of this investigation was therefore to document indigenous sugarcane landraces growing in Western Cameroon.

\section{Materials and Methods}

The present study was conducted in the Western Cameroon. This part of the country consists of two agro-ecological zones (AEZ). These zones included the Western high plateau in the West and North West regions and the Humid forest with monomodal rainfall in the Southwest region of Cameroon (Fig. A1). The Western high plateau lies at altitudes ranging between $1,100 \mathrm{~m}$ and $2000 \mathrm{~m}$ above sea level (ASL). The rainfall distribution is bimodal and range 1000 to $2,000 \mathrm{~mm}$ per annum, with two cropping seasons in the valleys and one on the mountains areas. This is the coldest part of the country, with temperatures ranging from 18 to $25^{\circ} \mathrm{C}$. The long wet season of 8-9 months from March to November and the high humidity generally over $80 \%$ ensures continuous presence of moisture in the air. The Humid forest AEZ in the Southern part of the country lies at altitudes ranging from 0 to $800 \mathrm{~m}$ ASL. This AEZ is characterized by forest / savanna mosaic vegetation with rain fall between 1,200 and 2,000mm per year from March to November. The temperature ranges from 22 to $32^{\circ} \mathrm{C}$ and the relative humidity is normal around $80 \%[9,10]$. Within these two zones, 66 villages were sampled based on earlier reconnaissance survey and altitudinal distribution (Fig. A1). These villages surveyed were: Upper Farms, Lower Farms, Molyko, Bolifamba, Ekona, Mammu, Muea, Bokova, Bonakanda, Mabanda, Konye, Eyang, Ashum, Bakebe, Faichang, Mbinjong, Egbekaw, Nchang, Besongabang, Diongo, Barombi kang, Kake, Ekumbe, Ekumbe Bonji, Kombone Bonji, Kumbone Bakundo, Nake, Bole, Ngongo, Mabonji Bakundu, Nganjo, Bekora, Lobe Estate, Ekondo Titi, Deponda, Bisingi, Funge, Mundemba, Teke, Etam, Ebonji Tombel, Mile 19 Tombel, Musung camp, 3 corners Tombel, Ngap, Bagem, Lewoh, Belluah, Beleuh, Seat of wisdom, Menji, Ndungated, Toula Ndizong, Johnny Baleng, Baleveng, Mbouda, Fongo Tongo, Foto, Dchang, Baleveng, Njinteh Bafut, Aghiati, Obang, Befang, Weh, Wum, Nkwen. These zones were chosen based on their significance in terms of sugarcane production for local consumption. These zones have been the subject of previous ethnobiological investigations regarding the medicinal uses of other plants. The community's economy is based on subsistence farming. The main crops are corn, beans and cocoyam. Both wild and cultivated vegetables supply daily family needs for food and health care.

\subsection{Surveys}

The survey for sugarcane was conducted between $20^{\text {th }}$ of February to the $5^{\text {th }}$ of April 2012. Villages in two agroecological zones were surveyed. These zones included the humid forest with monomodal rainfall in the Southwest of Cameroon and the Western high plateau in Northwest and Western Regions of Cameroon. The same villages were observed again in 2013 from the month of February to April. Collection sites were geo-referenced by GPS points using the Garmin Etrex Venture GPS.

In order to gather all the necessary data and fulfill the objectives of the survey, a set of various approaches were carried out in the field. Information about the agricultural framework of the crop diversity was obtained from the Regional Delegations of agriculture of the regions. Visits were made to the different villages concerned and contacts established with the chiefs and quarter heads to solicit their help in the research. In each of the villages, a general meeting was convened during which the purpose of the study, approach to be adopted and local participation were discussed. Semistructured interviews and discussions were done. The general design consisted of informants and their associated knowledge on sugarcane. Each study area was surveyed to locate both informants and sugarcane farmers' fields.

\subsection{Inventory}

The objectives of this study were explained to both the regional heads of agriculture, traditional heads and quarter heads. Only informants who were 20years old and above were included as sample informants. This age group was chosen because these individuals could legally account for their actions and the aged are well knowledgeable on the existing landraces in the study area. The survey was conducted in three stages. Survey regarding knowledge and/or uses, demographic and socio-economic information and landraces grown were recorded using semi - structured and open-ended questionnaire. Prior to the administration of questionnaire, conversations with the informants were held to elaborate on the objective of the study and to build on trust with the common goal to document and preserve the knowledge on medicinal value of sugarcane plant. Prepared semi - structured and open-ended questionnaires were administered to traditional healers, sugarcane farmers, vendors and traditional/quarter heads.

Group discussions were held and the Participatory Rural Appraisal approach (PRA) [11] was used. Indigenes expressed their knowledge in meetings convened by traditional and quarter heads on the sugarcane plant, the landraces, uses and the possible genetic erosion of the plant. These discussions consisted of mostly the elderly of age 50 years and above as they had a lot of information about the uses of sugarcane plant. All conversations were done in Pidgin English. 
Permission was obtained from farmers to visit their fields. On - the - farm observation was conducted to record the different sugarcane landraces grown and to collect sugarcane germplasm for conservation. Home gardens and sugarcane farmlands were visited and the different landraces were observed based on morphological characteristics used by [12]. The canes were identified using the local names. Sugarcane setts were randomly collected in the 66 villages. The top $1 / 3$ of the stalk contains many buds and a good supply of nutrients, was collected for the seed cane. The samples were labeled according to site of collection, landraces' name, collection's number and dated. Samples were preserved temporary in bags, transported and conserved in situ in the Faculty of Science, University of Buea research plot.

A total of 290 questionnaires were distributed out to 203 males and 87 females in the site of the study. The criteria for choosing the sample population were based on age, gender, social role. These criteria were used because it was not possible to obtain the participation of the whole population.

\subsection{Data Analysis}

Data on demographic and socio-economic characteristics of respondents, the uses and causes of genetic erosion of this plant were entered into an excel worksheet and were analyzed using Chi square, MINTAB version 16 statistics in Microsoft Excel 2007. Simple frequencies, tables and figures as well as percentages were produced for sugarcane landraces encountered and medicinal uses of sugarcane. The fidelity level (FL) of each landraces was calculated for the most frequently reported diseases or ailments as:

$$
\mathrm{FL}(\%)=(\mathrm{Np} / \mathrm{N}) \times 100,
$$

Where $\mathrm{Np}$ is the number of informants that claim a use of a plant species to treat a particular disease,

$\mathrm{N}$ is the number of traditional healers that use the plants as a medicine to treat any given disease [13]

Representative samples of landraces grown have been conserved in situ in the University of Buea, Cameroon.

\section{Results}

\subsection{Ages and Sex Distribution}

A total of 290 people responded during the survey in the two agro-ecological zones of Cameroon representing 204 males and 86 females. Of the 290 informants, (37.9\%) were between the age 41 and 50 years. Others were aged greater than 60years $(10.3 \%), 51$ and 60years $(27.5 \%), 31$ and 40 years $(15.5 \%)$ and less than 30years (8.6\%) (Fig. A2). The p value of the chi square test was 0.255 indicates that there was no association in the age distribution with respect to gender. Gender was not bias.

\subsection{Educational Level of Respondents}

Most of the farmers had attained formal education. $80.3 \%$ of them had attained primary education, $11.4 \%$ had secondary education. Other levels were tertiary $(2.4 \%)$ and no formal education was $5.8 \%$ (Fig. A3).

\subsection{Landraces Encountered}

This study revealed the usage of five local sugarcane landraces in the sampled villages (Table A1), which were as follows:

'Buea sugarcane': Stalk colour under wax layer was purple brown that becomes dark bronze with exposure to sun. Presence of growth cracks and ivory marks occurred occasionally and lacks bud groove. The leaf sheath margin is green with thin purple edges and has moderate amount of leave sheath pubescence. The auricle is lanceolate, internodes cylindrical and bud triangularly pointed. The ligule is orbicular crescent and the dewlap is rhomboid with dark olive green colour.

'Strong canda': Stalk colour under wax is purple brown, which becomes dark purple on exposure sun. This cane has no growth cracks, ivory marks and bud groove. The leaf sheath margin is purplish with thin red necrotic margins and moderate amount of leave sheath pubescence. The auricle is lanceolate, the internode is bobbin shaped and the bud is ovate in shape. This cane has a crescent shape ligule and the dewlap is deltoid with horizontal baseline.

'Strong bark': Stalk colour under wax is greenish yellow and becomes yellow on exposure to sun. There is absence of growth cracks, ivory marks and bud groove. Leaf sheath is highly pubescent, necrotic with a band of red lines. Auricle is lanceolate with tufts of hair, the internode is cylindrical and the bud has an oval shape. The ligule is crescent light brown and the dewlap is deltoid with horizontal baseline.

'Yellow cane': Salk colour under wax is green yellow and becomes pale yellow on exposure to sun. There is absence of growth cracks, ivory marks and bud groove. Leaf sheath has moderate amounts of pubescence with necrotic leaf margins. Auricle is long and falcate, necrotic and prominent. Internode is bobbin shaped, with dark brown orbicular crescent ligule. The bud is beaked shaped. The dewlap is deltoid with downward-slopping base lines.

'Bakweri sugarcane': Stalk colour under wax is reddish and becomes dark red with exposure to sun. There is absence of growth cracks and ivory marks. There is presence of a shallow and short bud groove. Leaf sheath is long, highly pubescent and margins serrated. The auricle is lanceolate, internode is obconoidal in shape. The bud has an obvate shape. The ligule is crescent and dewlap squarish-subcrescent with downward slopping baseline.

\subsection{Uses of Sugarcane}

Sugarcane was grown mainly for food, medicinal uses, income generation and for cultural manifestations (Fig. A4). This figure reveals that the farmers were growing the plant for more than one reason. Canes were mostly grown for income generation and food while canes were least used for cultural manifestation. From responses obtained from the local population, it was realized that the five landraces could 
treat 21 ailments as shown in (Table A2). Of the five landraces, 'Buea sugarcane' recorded the highest fidelity level and the least was 'Bakweri sugarcane' which was used only in Fako Division in the Southwestern region in the Humid forest AEZ of Cameroon (Table 3). Other ingredients were used alongside the medications to make it effective. The oral route was the most employed route $(85 \%)$. All the canes were used for the treatment of one or more ailments. Some of the treatments were peculiar to some particular tribes (Table 4).

Despite the high rate of utility of this plant in these agroecological zones of Cameroon, generally, its production was threatened by many factors. The causes of genetic erosion were lack of market for the sale of sugarcanes, shortage of land due to urbanization, introduction of other cash crops and diseases (Fig 5). From the chi square test of similarity, there was no association between the causes of genetic erosion and sites $\left(\chi^{2}=4.591, p=0.597\right)$. In other words, causes of genetic erosion could be said to be similar across sites.

\section{Discussions}

The present research aimed to collect local sugarcane cultivars and to obtaining important indigenous information about sugarcane plant. Demographic and socio-economic characteristics of the respondents showed that majority of the farmers $(37.9 \%)$ were between the age of 41 and 50 . Others $51-60$ (27.5\%), 20-30(10.6\%), 31-40(8.6\%) and >60(10.3\%) were also involves in sugarcane production. This implies that the young generations were still attending school and some have left the villages for urban centers for better paying jobs.

More males $(70 \%)$ than females $(30 \%)$ were involved in sugarcane cultivation. Therefore, the men were well knowledgeable in sugarcane cultivation than the females. This might be due to the fact that sugarcane production is so strenuous and labour intensive. Both males and females have also been observed in sugarcane production in other countries [14].

Most of the farmers had obtained formal education. A higher $\%$ of the farmers had only primary education. Only $11 \%$ had secondary education. None was observed at higher educational level. Those who attained higher educational level were on better paid jobs.

This study provides information on five local landraces of sugarcane plant used in the communities. The most widely grown sugarcane landrace was the 'Buea' sugarcane'. This landrace was found in (79.5\%) of the fields. The least grown landrace was 'Bakweri sugarcane' that was grown only in 3 of the fields (1.2\%) and used only by the 'Bakweries' in the Southwest region. 'Buea sugarcane' might be popular because the setts were brought to Buea by the Europeans who came for plantation agriculture. The labourers took this cane as snacks during break.

Sugarcane was mainly grown for income generation $(31.7 \%)$. Most of the farmers reported selling sugarcane was a source of livelihood. Reference [15] reported that sugarcane was a major farm enterprise, contributing about
$90 \%$ to farm income. This is contrary to the study carried out by [16], in which there was a drop in income from sugarcane due to increase in land value. Although there is a drop in income, sugarcane still has an income value as it is still grown in abundance [8]. It was also grown as food, as some of the elderly farmers reported taking sugarcane as snacks when they retire from farming activities. This might be due to the fact that sugarcane contains glucose which is a source of energy and revitalizes the body. It can be consumed by people of all ages and social strata during summer [17]. The leaves were always available as forage for animals. Extracts of sugarcane has been fed onto chicks and has resulted to increase in body weight [18]. Equally, [19] also investigated the fact that whole cane could be used as roughage for lactating dairy cows. Similar results were also reported by [20]. Sugarcane was used for the treatment of many ailments when mixed with other ingredients. Many authors have reported on the medicinal values of sugarcane in other countries $[21,22]$. Though only stem and leaves of sugarcane were used as medicine in the study, root has been reported to be very useful in Ayurvedic medicine [3]. Some of these ailments treated with sugarcane have also been treated by other plants [23]. The plant has been reported to be a feedstock for first-generation biofuel in many countries [7], but its production levels need not diminish food security.

Generally, the causes of genetic erosion of this crop were numerous. The most important cause of genetic erosion as mentioned by many farmers was the lack of market for the canes and lack of farmland. When choosing varieties, farmers consider yield potential as well as other production and consumption attributes [24]. Most of the farmers rely solely on agriculture for all their family needs and so they gave high priority to crops that were in high demand and neglected or sometimes dropped those with low demand. As such, little attention was given to sugarcane production. Rather other food crops like vegetables, cocoyam, plantains and cash crops like cocoa and coffee were grown in preference to sugarcane. Population growth, urbanization, developmental pressures on the land resources causes the destruction of the sugarcane crops and their wild relatives [26, 27]

\section{Conclusion}

Five local sugarcane landraces were of significant value in the communities. Therefore, the general public should be enlightened on the danger of losing these canes. This therefore implies that the plant is paramount to conservation based on degradation as a result of diseases, need for farm land for other economically valuable crops and urbanization. Genetic erosion of this plant should be considered. For this reason, the documentation and conservation of the existing biodiversity should be encouraged.

\section{Acknowledgement}

The authors are thankful to the University of Buea, Regional and divisional delegations of Agriculture for their 
educational supports and directories, and to all informants of knowledge with us. the research area, who were willing to share their indigenous

Table A1. Frequency of canes commonly grown in Western Cameroon.

\begin{tabular}{lll}
\hline Common name & Number of field grown & Frequency \\
\hline Buea sugarcane & 195 & $79.5 \%$ \\
Bakweri sugarcane & 03 & $1.2 \%$ \\
Yellow cane & 63 & $25.7 \%$ \\
Strong bark & 32 & $13.1 \%$ \\
Strong canda & 45 & $18.4 \%$ \\
\hline
\end{tabular}

Table A2. Medicinal uses of sugarcane landraces from Western Cameroon.

\begin{tabular}{|c|c|c|c|c|c|c|c|}
\hline Ailments & Landraces & Part used & Mixture & Administration & Dosage & Route & Duration \\
\hline Black spot & Buea & juice & Dicoc & Apply M/A & $100 \mathrm{ml}$ & Ext & A week \\
\hline Body irritation & Buea /Strong bark & juice & Dicoc & Apply M/A & $100 \mathrm{ml}$ & Ext & A week \\
\hline Child birth & Bakweri/Strong canda & juice & Dicoc & Drink/chew & A piece & oral & A day \\
\hline Conjunctivitis & Buea / Strong canda & juice & Dicoc & Drops M/E & 3drops & oral & 3 days \\
\hline cold & Buea/ Yellow cane / Bakweri & juice & Dicoc & Drink,M/A/E & $1 / 2$ glass & oral & 2 days \\
\hline Cough & Buea & juice & Dicoc & Drink,M/A/E & $1 / 2$ glass & oral & 2 days \\
\hline Defective eye & Buea / Bakweri & juice & Dicoc & Drops M/E & 3drops & oral & 3 days \\
\hline Dysentery & Yellow cane / Buea & juice & Concoc & Drink,M/A/E & $1 / 2$ glass & oral & 5 days \\
\hline Diarrhea & Yellow cane / Buea & juice & Concoc & Drink,M/A/E & $1 / 2$ glass & oral & 5 days \\
\hline Erectile dysfunction & Bakweri & juice & Concoc & Drink/chew & $1 / 2$ glass & oral & Until recovery \\
\hline Fatigue & Buea, Yellow cane, Strong bark & juice & Decoc & Chew/drink at all time & $1 / 2$ glass & oral & Until recovery \\
\hline Fever & Buea & juice & Dicoc & Drink $\mathrm{M} / \mathrm{E}$ & $1 / 2$ glass & oral & 2 days \\
\hline Fungi & Strong bark & leaves & Dicoc & Apply M/A & $100 \mathrm{ml}$ & Ext & A week \\
\hline Gastritis & Strong canda/ Strong bark & juice & Dicoc & Drink M/A/E & $1 / 2$ glass & oral & A week \\
\hline Intestinal trouble & Buea / Strong canda & juice & Concoc & Drink M/A/E & $1 / 2$ glass & oral & Until recovery \\
\hline Kidney functioning & Buea / Strong canda & juice & Dicoc & Drink M/A/E & $1 / 2$ glass & oral & Until recovery \\
\hline Liver problem & Buea/ Yellow cane & juice & Concoc & Drink $\mathrm{M} / \mathrm{E}$ & $1 / 2$ glass & oral & Until recovery \\
\hline Scanty urination & Buea & juice & Concoc & Drink $\mathrm{M} / \mathrm{A} / \mathrm{E}$ & $1 / 2$ glass & oral & A week \\
\hline Sore throat & Strong bark & juice & Concoc & Drink M/A/E & $1 / 2$ glass & oral & 2 days \\
\hline Vagina itches & Buea /Strong bark & juice & Concoc & Drink $\mathrm{M} / / \mathrm{E}$ & $1 / 2$ glass & oral & 3 days \\
\hline Wounds & Yellow cane/ Buea & Juice/ Leave & Concoc & Clean M/A & $100 \mathrm{ml}$ & Ext & Until yields \\
\hline
\end{tabular}

Ext, external use; Dicoc, decoction; Concoc, concoction; M, morning; A, Afternoon; E, evening

Table A3. Sugarcane landraces from Western Cameroon: their major medicinal uses and fidelity level.

\begin{tabular}{lll}
\hline Landrace & Medicinal uses & Fidelity level (\%) \\
\hline 'Buea cane' & Black spot, body irritation, cold, fever, fatigue conjunctivitis, cough, defective eye, diarrhea, dysentery, & 76.2 \\
'Strong bark' & kidney functioning liver problems, scanty urination, vagina itches, wounds & 28.6 \\
'Yellow cane' & Body irritation fatigue, fungi, gastritis, sore throat, vagina itches & 28.6 \\
'Strong canda', & Cold, diarrhea, dysentery, liver problem, wound & 23.8 \\
'Bakweri cane' & Child birth, conjunctivitis, fatigue, kidney problem, intestinal trouble, & 19.0 \\
\hline
\end{tabular}

Table A4. Traditional treatment common to tribes in western Cameroon.

\begin{tabular}{|c|c|}
\hline Method of use. & Place of practice \\
\hline $\begin{array}{l}\text { The traditional dance call 'elephant dance' is done using "Bakweri" sugarcane. The cane is eaten by the } \\
\text { masquerade as an indication that sugarcane is food source of elephant in the forest. } \\
\text { The juice is also applied on to a woman during her first pregnancy as a sign of purification. Sugarcane juice is } \\
\text { also rubbed on exposed parts of the body while working in the farms or during wake keeping in the open air to } \\
\text { repel mosquitoes and other biting insects. }\end{array}$ & $\begin{array}{l}\text { "Bakweries' and Bayangs of the } \\
\text { Southwest region }\end{array}$ \\
\hline At difficult labour, the fresh juice is given to the woman for her to have energy to push out the baby. & $\begin{array}{l}\text { "Bakweries" and "Orokos" of the } \\
\text { Southwest region. }\end{array}$ \\
\hline $\begin{array}{l}\text { The rind is used to scrap ring worm and other dermatological infections and the burnt ash of the chaff is mixed } \\
\text { with kennel oil and applied on the affected area. } \\
\text { The burnt ash is also mixed with the mucous of snail and applied on the head of a baby to treat fontanel. } \\
\text { The burnt chaff is ground, mixed with lime stone and palm oil, taken orally to treat stomach ache. } \\
\text { An inflamed part of the body is given small cuts and sugarcane stem is burnt mixed with 'masepo', applied on the } \\
\text { affected part. }\end{array}$ & Bayangs of the South west region. \\
\hline
\end{tabular}




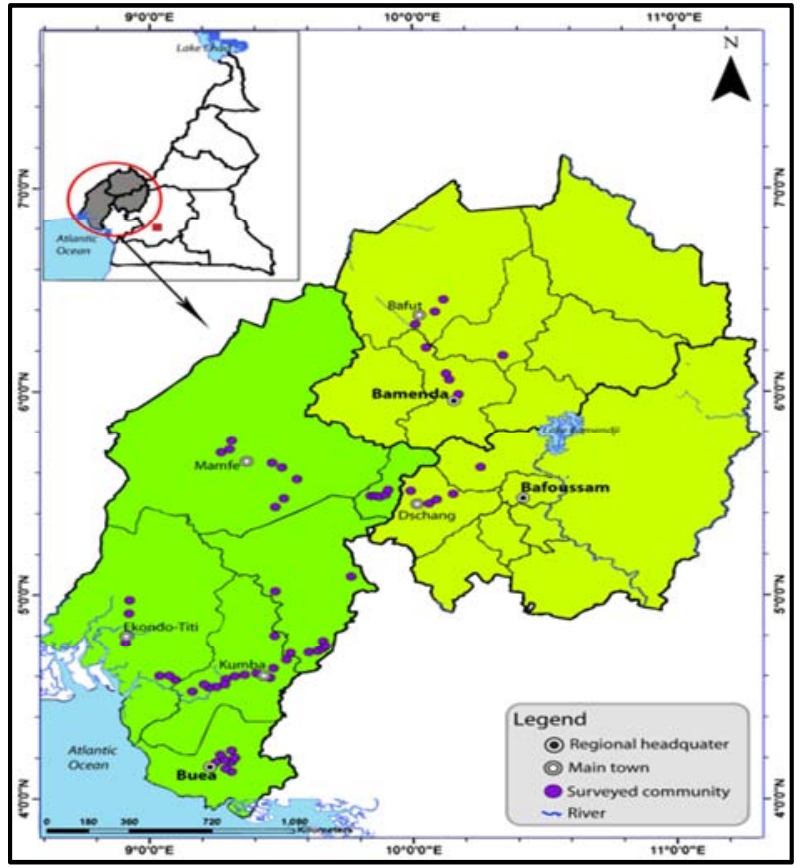

Fig. A1. Sugarcane Sampled sites in Western Cameroon.

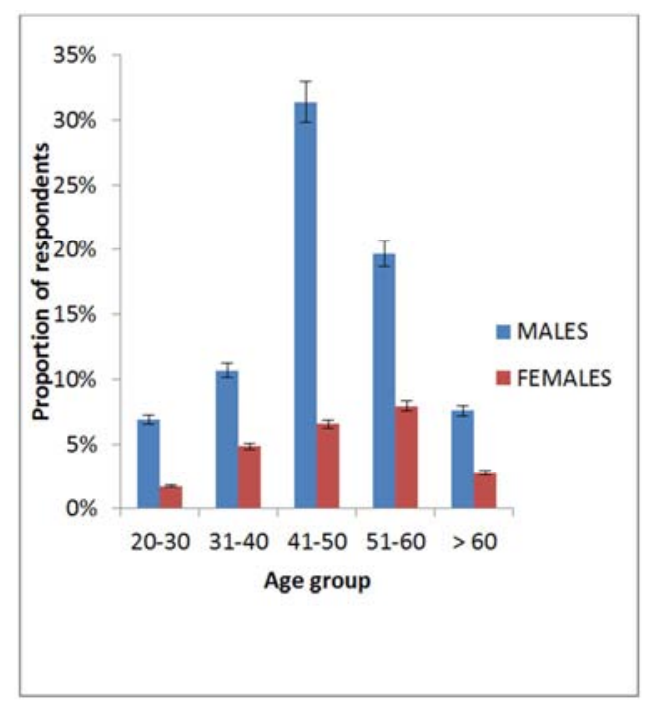

Fig. A2. Age and Sex distribution of Sugarcane informants.

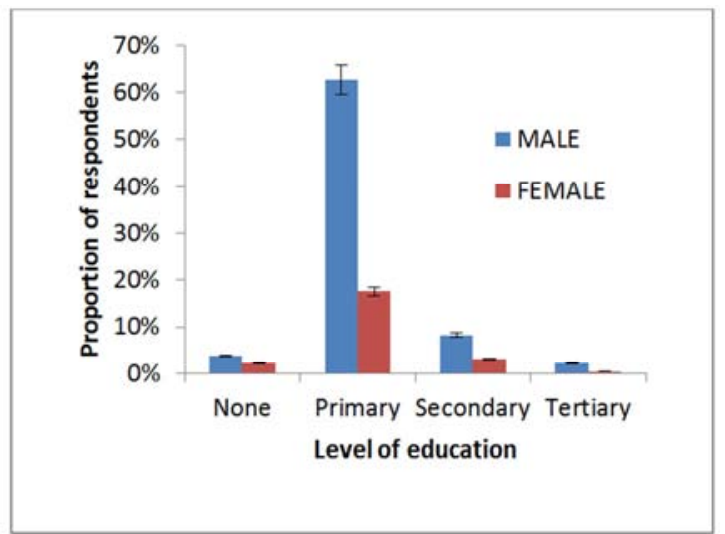

Fig. A3. Gender and the level of education of informants from western Cameroon.

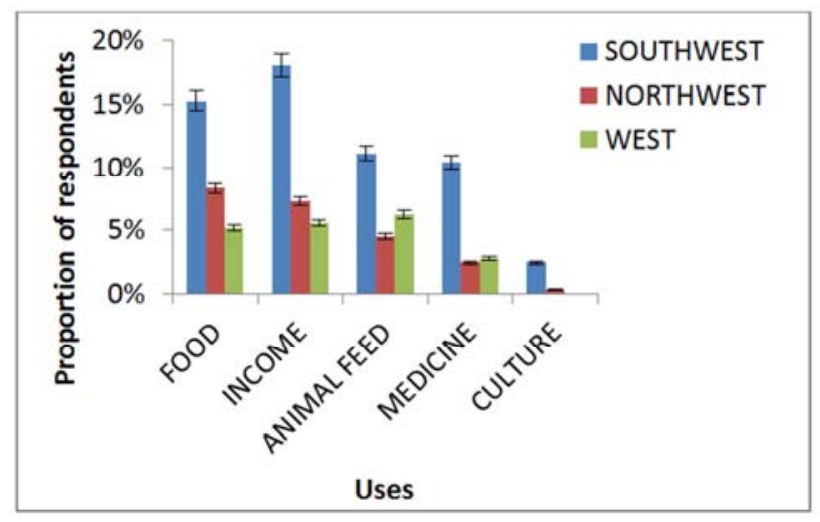

Fig. A4. Uses of sugarcane in Western Cameroon.

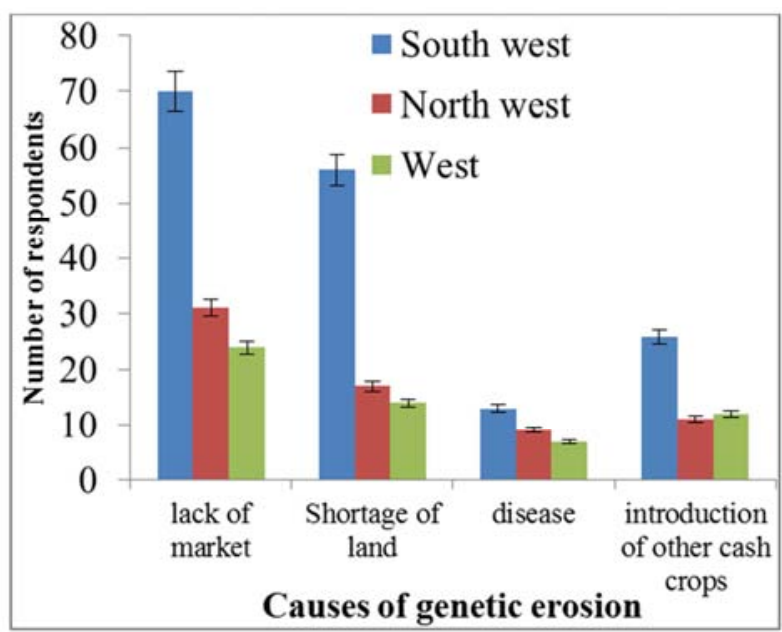

Fig. A5. Possible causes of genetic erosion of sugarcane in Western Cameroon.

\section{References}

[1] Marion, D., Oriol, P. and Domainque, R. 2002. The establishment of a sugarcane variety: Evaluation network for West and Central African Countries. Proceedings of South African Sugarcane Technology Association. 76.

[2] Rahmatullah, M., A. Hasan, W. Parvin, Md. Moniruzzaman, A. Khatun, Z., Khatun, F., Israt, J., and Jahan, R. 2010. Medicinal plants and formulations used by the Soren clan of the Santal tribe in Rajshahi District, Bangladesh for treatment of various ailments. African Journal of Traditional Complement Alternative Medicine 9(3):350-359.

[3] Kadam U. S., Ghosh, Strayo, S. B., Suprasanna, De P., Devasagayam, T. P. A. and Bapat, V. A. 2008. Antioxidant activity in sugarcane juice and its protective role against radiation induced DNA damage. Food Chemistry 106: 11541160 .

[4] Singh, A., Lal, U. R. Mukhtar, H. M. Singh, P. S. Shah., G. and Dhawan, R. K. 2015. Phytochemical profile of sugarcane and its potential health aspects. Phamacognosy Review 9 (17): 45-54.

[5] Almaraj, V. A. and Balasundaram, N. (2006). The taxonomy of the members of 'Saccharum complex.' Genetic Resources and Crop Evolution 53: 35-41. 
[6] Bele YM, Focho DA, Egbe E A, Chuyong BG. 2011. Ethnobotanical survey of the uses of the members of Annonaceae around Mount Cameroon African. Journal of Plant Sciences (17):45-54. doi: 10.4103/0973-7847.156340.

[7] Graham von M., Lorren H., Maxwell M. and Alan B. 2009. Analysis of opportunities for biofuel production in subSaharan Africa. Environment Brief. www.cifor.cgiar.org, 19/2/2016.

[8] Food and Agriculture Organization (FAO) 2008. The state of food and agriculture: Biofuels - prospects, risks and opportunities. FAO, Rome.

[9] Egbe E. A. and P. T. Tabot, 2011. Carbon sequestration in eight woody non-timber species and their economic potentials in South west Cameroon. Applied ecology of the Environmental Research 9: 369-385.

[10] Focho DA, Ndam WT, Fonge BA (2009a). Medicinal plants of Aguambu-Bamumbu in the Lebialem highlands, southwest province of Cameroon. African Journal of Pharmacology 3(1):1-13.

[11] Chambers, R. 1994. Participatory Rural Appraisal (PRA): Analysis of Experience. World development 22(9): 1253-1268.

[12] Artschwager, 1948a. Vegetative characteristics of some wild forms of Saccharum and related grasses. U.S. Department of Agricultural technological Bulletin 69pp 951.

[13] Alexiades M. N. 1996. Selected guidelines for ethnobotanical research: A Field Manual. Advances in Economic Botany, 10. The New York Botanical Garden, Bronx.

[14] Girei A. A. and Giroh D. Y. 2012. Analysis of the Factors Affecting Sugarcane (Saccharum officinarum) Production under the Out growers Scheme in Muman Local Government Area Adamawa State, Nigeria. Advances in Agriculture, Sciences and Engineering Research 2(5): 158 - 164.

[15] Singh A, Lal UR, Mukhtar HM, Singh PS, Shah G, Dhawan RK 2015 Phytochemical profile of sugarcane and its potential health aspects. Pharmacognocy Review 5(3):1-11.
[16] Smith, M., Poggio, M. J., Thompsom, M. and Collier, A. 2014. The economics of pesticide management practices on sugarcane farms: Final synthesis Report. Department of Agriculture, Fisheries and Forestry (DAFF), Queenland.

[17] Hammond, A. L. 1977. Alcohol: A Brazilian answer to the energy crisis. Science 195:564-566.

[18] El-Abasy, M. M., Motobu, M., Sameshima, T., Koge, K. and Hirota Y. 2003. Ajuvant effect of sugarcane extract (SCE) in chicken. Journal of veterinary science 65: 117-119.

[19] Kawashima, T., W. Sumamal, P. Pholsen, R. Chaitiang and Boonpakdee, W. 2002. The use of sugarcane stalks for feeding lactating cows. Asian-Australian Journal of Animal Science 15 (2): 205-208.

[20] Suksombat, W. and Junpanichcharoen, P. 2005. Feeding of Sugarcane Silage to Dairy Cattle during the Dry Season. Asian-Australian Journal of Animal Science 18(8): 1125-1129.

[21] Savitha S. 2012. Ayurveda Medicinal Properties of Sugarcane and Sugarcane Juice. Pp 13.

[22] Subbannayya K., Bhat, G. K., Shetty, S. and Junu V. G. 2007. How safe is sugarcane juice. Indian Journal of medical Microbiology. 25(1):73-74.

[23] Ndah, N. R. A. E. Egbe, E Bechem, S. Asaha, T. Yengo, E. L. Chia., and Eyenieh N. M. 2013. Ethnobotanical study of commonly used medicinal plants of the Takamanda Rainforest South West, Cameroon. African Journal of Plant Science 7(1): 21-34.

[24] Freemark, K. E., Boutin, C. and Keddy, C. J. 2002. Importance of farmland habitats for conservation of plant species. Conservation Biology 16: 399-412.

[25] Gao, L. Z. (2003). The conservation of Chinese rice biodiversity: genetic erosion, ethnobotany and prospects. Genetic Resources and Crop Evolution 50: 17-32.

[26] Saunders, D. A., Hobbs, R. J. and Margules, C. R. (1991). Biological consequences of ecosystem fragmentation: a review. Conservation Biology 5:18-32. 